\title{
A New Framework to Evaluate Passenger Interactions at Platform Train Interfaces
}

\author{
S. Seriani ${ }^{1}$, T. Fujiyama ${ }^{2}$ and G. De Ana Rodriguez ${ }^{3}$ \\ ${ }^{1}$ Department of Civil Environmental and Geomatic Engineering \\ University College London, United Kingdom and \\ Faculty of Engineering and Applied Sciences, Universidad de los Andes, Chile \\ ${ }^{2}$ Department of Civil Environmental and Geomatic Engineering \\ University College London, United Kingdom \\ ${ }^{3}$ Rail \& Underground Transport Planning, Transport for London \\ United Kingdom
}

\begin{abstract}
Platform train interfaces (PTIs) are spaces with high interactions between passengers boarding and alighting. A simple framework is proposed to help designers and planners to identify and benchmark the degree of interaction when crowd management measures are used such as platform edge doors (PEDs). Firstly, a conceptual model is created to represent the interaction problems, followed by the definition of variables. Then, the degree of interaction is defined based on the density and perception of risk. Finally, the results are presented in a matrix that groups the variables according to the area where the interaction happens, and to the type of users that are affected. As a case study, the framework is applied in this paper to two existing stations (with and without PEDs). The results show that the new framework is able to describe well the phenomena of high interactions and can be used to evaluate suitable crowd management measures in railway infrastructure and to communicate interaction problems in a simple and effective way.
\end{abstract}

Keywords: pedestrian, matrix, behaviour, interaction, platform, station

\section{Introduction}

Platform train interfaces (PTIs) are considered one of the most unsafe spaces for passengers boarding and alighting. In the case of the UK railway network, a strategy has been launched to reduce the 3 billion passenger interactions made every year, which represent $48 \%$ of the fatality risks at the PTI [1]. This complex space presents different risks and hazards for passengers. Accidents can occur during boarding and alighting or simply at the platform edge, even when there is no boarding or alighting.

To improve safety conditions at PTIs, crowd management measures can be used. Crowd management at stations is defined as "the rational administration of the 
movement of people to generate adequate behaviour in public spaces to improve the use of pedestrian infrastructure" [2, p.76].

As an example of crowd management measures, some stations on the London Underground (LU) network have platform edge doors (PEDs) and a single line on the platform in front of each door, which act as door position indicators on platforms to highlight where the doors are going to be. PEDs have been installed in different metro stations worldwide $[3,4,5]$. On the LU, PEDs work as sliding barriers that open simultaneously with the train doors and hence prevent passengers falling onto the track. Despite the benefits of using PEDs, only nine stations on the LU network have these elements. According to [6] the limitation to install PEDs arises from the differences in trains (e.g. different door width) and the variances in the configuration of platforms (e.g. PEDs are cumbersome to curved platforms).

The use of crowd management measures such as PEDs could help to minimize risks or any hazard at PTIs. But it is not only about safety. Crowd management measures can also help operators to improve the performance of the boarding and alighting process by reducing the time each train remains stopped at the station [2]

Despite the benefits of implementing crowd management measures, there is a lack of frameworks to analyse their effect on the behaviour and interaction of passengers boarding and alighting. According to [7], effective indicators have been developed to measure the performance of railway infrastructure. However, performance indicators for reliability, availability, maintainability, and safety (RAMS), capacity, punctuality, etc. are mainly focused on rail infrastructure rather than crowd management. The problem is that isolated crowd management measures do not give enough information for decision making, therefore the type of measures, what variables to study and their impact, should be compiled, analysed and converted into a framework.

The aim of this paper is to create a new framework based on matrices to analyse interaction problems at the PTI during the boarding and alighting process, when crowd management measures are used. The specific objectives are to:

- create a conceptual model to represent the interaction problems in the boarding and alighting process;

- identify the main variables that affect the behaviour and interaction of passengers at the PTI;

- use a matrix to present the interaction problems;

- study the formation of lanes and location of passengers on platforms when door position indications on platforms are used;

- make recommendations to reduce the interaction at the PTI.

This paper has six sections, including this one. In Section 2, a summary of existing studies to analyse interaction is described. Next, in Section 3, the new framework to study interaction problems is explained. Section 4 shows the results of the application of the new framework at existing stations. In Section 5, the results are discussed. Finally, in Section 6, the conclusions are presented. 


\section{Existing studies to analyse interaction}

The problems of interaction between passengers are related to the concept of crowds. The definition of crowds started with the work of Still [8], in which he defined crowd dynamics as "the study of the how and where crowds form and move above the critical density of more than one person per square metre" [9, p. 93]. The author also defined the concept of crowd behaviour to understand the motivation, competition, and type of passengers in a crowd.

The behaviour of crowds at PTIs can be described in two situations. Firstly, when passengers on the platform are waiting to board the train or forming queues around the doors. When queues reach a Level of Service (LOS) according to Fruin [10], equal to $\mathrm{F}$ or a density of more than five passengers per square metre $\left(0.2 \mathrm{~m}^{2}\right.$ per passenger $)$, then passengers experience high interaction with high potential to fall onto the track.

This high interaction also happens in a second situation known as the dynamic process of boarding and alighting, in which a density of more than 2 passengers per square metre $\left(0.5 \mathrm{~m}^{2}\right.$ per passenger or LOS F in [10]) is considered a critical density with sporadic flows and frequent stops. In this situation, passengers boarding can be a

-up carriage, in which all passengers boarded the train (i.e. no passengers were waiting on the platform for the next train). Therefore, it would be interesting to investigate if this behaviour also occurs in operating conditions in metro stations.

The PTI will reach a critical density when the total number of passengers on the platform exceeds the capacity of the platform. The LOS of Fruin [10] could be used to identify the degree of congestion on the platform. The LOS goes from Level A (free flow) to Level F (critical density), in which LOS = E is defined as "at capacity". However, for Evans and Wener [14], average values of density seem not to be the ideal way to represent interactions in train environments. These authors argued that an overall density does not say if passengers are stationary or moving in a particular way. To solve this, Seriani et al. [13] proposed to divide the platform into semicircular layers of $50 \mathrm{~cm}$ each and count the number of passengers boarding and alighting in each layer before and after the train stopped at the station. These authors found that the density by layers is more representative of the interaction than the overall density. 
In terms of modelling, crowds could be represented using Newton's Law. Yin et al. [15] used the kinetic, potential and internal energy of passengers to describe the local and global crowd energy at metro stations. Other authors [16] proposed a model to measure crowding in railway passengers and identify the effect on the level of stress and feeling of exhaustion. The authors included psychological aspects of crowds (dense, disorderly, confining, chaotic, disturbing, cluttered, unpleasant), evaluation of the environment where the crowd is situated (stuffy, smelly, noisy, hot), and how crowds react in specific situations (squashed, tense, uncomfortable, distracted, frustrated, restricted, hindered, stressful, irritable).

The inclusion of psychological aspects is also analysed by Cox et al. [17]. The authors stated that there is a difference between density and crowding. A high-density situation is related to the physical environment and not necessary considered as crowded with a high level of stress. RSSB [18] defines crowding as a physical measurement, i.e. as a function of density and capacity on the platform and train, but also with a psychological dimension which is more about the perception of risk and safety. Recently, Kim et al. [19] identified that passengers at metro stations tend to avoid delays, the stress of crowding, other passengers, or any risk related to sexual harassment.

For Still [9, 20], crowds are also related to risk and safety perception. The author stated that conventional risk assessment documents are not the ideal alternative to study crowds. Many of these documents overestimate risks or use "cut and paste" solutions from other manuals. Therefore, the format used in this type of report usually does not help to achieve a good comprehension of the risk problems. Moreover, Still $[9,20]$ reported that most environments present high levels of risk when there are problems in design, information, and management. In addition, he suggested that high-density environments will be reached in three categories: ingress, circulation, and egress. The author combined this into a matrix named DIM-ICE model, which is used to compare a normal and an evacuation situation. The DIM-ICE model could be combined with the RAMP analysis to model crowds [9]. With RAMP, it would be possible to identify the routes, areas, movement and profiles of the crowd. All these tools could be complemented with diagrams and pictures, using colours, maps, and codes.

Recently, different frameworks have been developed to evaluate the safety and efficiency of pedestrians in public transport environments. For example, [21] reported a new framework to study the safety of pedestrians at street level. The safety of pedestrians is affected by a combination of the built environment (land use, demographics, transit supply and road network), the risk exposure (pedestrian activity, traffic volume, and motor-vehicle operating speed), and the geometric design (road width, numbers of lanes, presence of marked pedestrian crossings, etc.) at a microscopic level. The authors used regression techniques to identify the relationship between those variables.

In the case of evacuation in metro stations, the standard for the design of the metro in China [22] is to evacuate the platform in less than 6 minutes, which is $33 \%$ higher 
than the USA standard (less than 4 minutes, according to [23]). Considering these standards, the framework of [24] was created as a function of the type of station (e.g. two side platform or island station), layout (e.g. number of stairs), safety elements (e.g. platform edge doors), alarming system (e.g. smoke detection ventilation), type of fire (train on fire stopped at station, fire in public spaces such as concourse and fire in railway tunnel) and type of passengers (in train, waiting on platform or concourse, staff on platform or concourse). As a result of the framework, the evacuation time was calculated and a strategy was adopted (e.g. opening of platform edge doors, all escalators up-going from platform to concourse or all automatic gate passage should be opened). Similarly, [25] proposed an operational framework to reduce the discomfort of passengers in the case of failure at metro stations. The authors used an optimisation model to identify the relationship between the network performance (rail infrastructures, rolling stock, signalling system and planned timetable), the demand level, and the failure context. The output of the model is the reduction of the train speed and the generalised cost for passengers. The authors found that if the headway increases, then the number of passengers boarding will increase too, affecting the congestion at the station. Although [24] and [25] studied metro stations from the point of view of the quality of the service ( therefore, including passenger discomfort) rather than the service punctuality, the strategies that were used measured the consequences of evacuation scenarios or when a breakdown occurred, but not for normal situations with high densities. Recent studies [26] identified that existing frameworks allow one to identify and quantify hazards at metro stations, however they could not address the relationship between these hazards. To solve this the authors developed a metro operational hazard network (MOHN) based on accident databases, government reports, expert interviews, and modelling.

Despite the important research related to crowds, the development of new frameworks is mainly based and focused on sporting events, street level and evacuation scenarios in metro stations, rather than the PTI when crowd management measures are used. In addition, existing frameworks are focused on crowds (e.g. evacuation of whole platform), but not on individuals (e.g. spaces with more interaction at the congested door). Therefore, new research is needed to create a more elaborate framework to study interaction problems in the boarding and alighting at the PTI. In particular, this work will focus on the behaviour and interaction of passengers in the London Underground, however, it could be expanded to any conventional rail or LRT system.

\section{A new framework BAMBI}

A new framework to study the behaviour and interaction of passengers boarding and alighting is proposed. This framework is named BAMBI (Boarding and Alighting Matrix on Behaviour and Interaction) and consists of four stages described below.

\subsection{Conceptual model}

Firstly, a conceptual model is created to represent the interaction problems on the PTI area (see Figure 1). Rectangles are used to represent the main infrastructure and 
ar

e.g. if they are standing beside the doors or in front of them) can be obtained.

The conceptual model also helps to understand the movement of passengers boarding and alighting. The behaviour and interaction in the boarding and alighting process should be analysed at the critical door of each platform. At the critical door, the platform is divided into concentric layers of $50 \mathrm{~cm}$, each using the platform conflict area (PCA) proposed by Seriani et al. [13]. According to these authors, passengers' interaction can be classified into three categories: interaction between passengers boarding (only boarding), between passengers boarding and alighting (when there are simultaneous movements), and between passengers alighting (only alighting). The use of layers helps to identify which part of the platform is more congested and how close passengers are to the doors. As an example, in Figure 1, passengers boarding are closer to the doors, and therefore considered an obstacle for those who are alighting, producing a collision of flows at the PTI.

\subsection{Variables}

Secondly, the variables that affect behaviour and interaction of passengers at the PTI are identified and classified according to Seriani and Fernandez [30]. Three groups of variables are considered: physical, spatial, and operational. Table 1 shows the variables that should be included in BAMBI, which are supported by laboratory experiments and field studies. Physical variables are defined as those which are related specifically with dimensions supported by experiments [30, 31, 32, 33, 34, 35, 36] and field studies $[37,38,39,40]$. In the case of spatial variables, experiments $[2,33$, $42,43]$ and field studies [40, 41, 44, 45, 46, 47] are considered as those circulation elements that could be used to change the behaviour of passengers. In the case of operational variables, the classification in Table 1 is focused on how the interaction can be measured. For example, according to Seriani et al. [13] the level of interaction is influenced by four operational variables: formation of lanes, types of queues, density by layer, and distance between passengers.

\subsection{Risk assessment}

Thirdly, the degree of interaction between passengers is defined as high, medium or low based on the density and perception of risk. This is based on the concept of critical density defined in $[9,10,48]$, which is related not only to the number of passengers 
per square metre of physical space, but also to the risk of accidents presented at the PTI. The authors in $[9,10,48]$ state that a high risk will be obtained when there is more than 2 passengers per square metre on walkways, or more than 4 pass $/ \mathrm{m}^{2}$ for static movement of passengers. With respect to the risk, five factors can be observed at the PTI following the classification reported in [1]: slips or trips or falls (e.g. misjudged the vertical gap), encumbrances (e.g. encumbered by suitcases, pushchairs, bikes, or other baggage), rushing or running (e.g. ra

e.g. being struck by a train while on the platform arising from a drunk passenger), and hazard on platform (e.g. walked on cracked pavement).

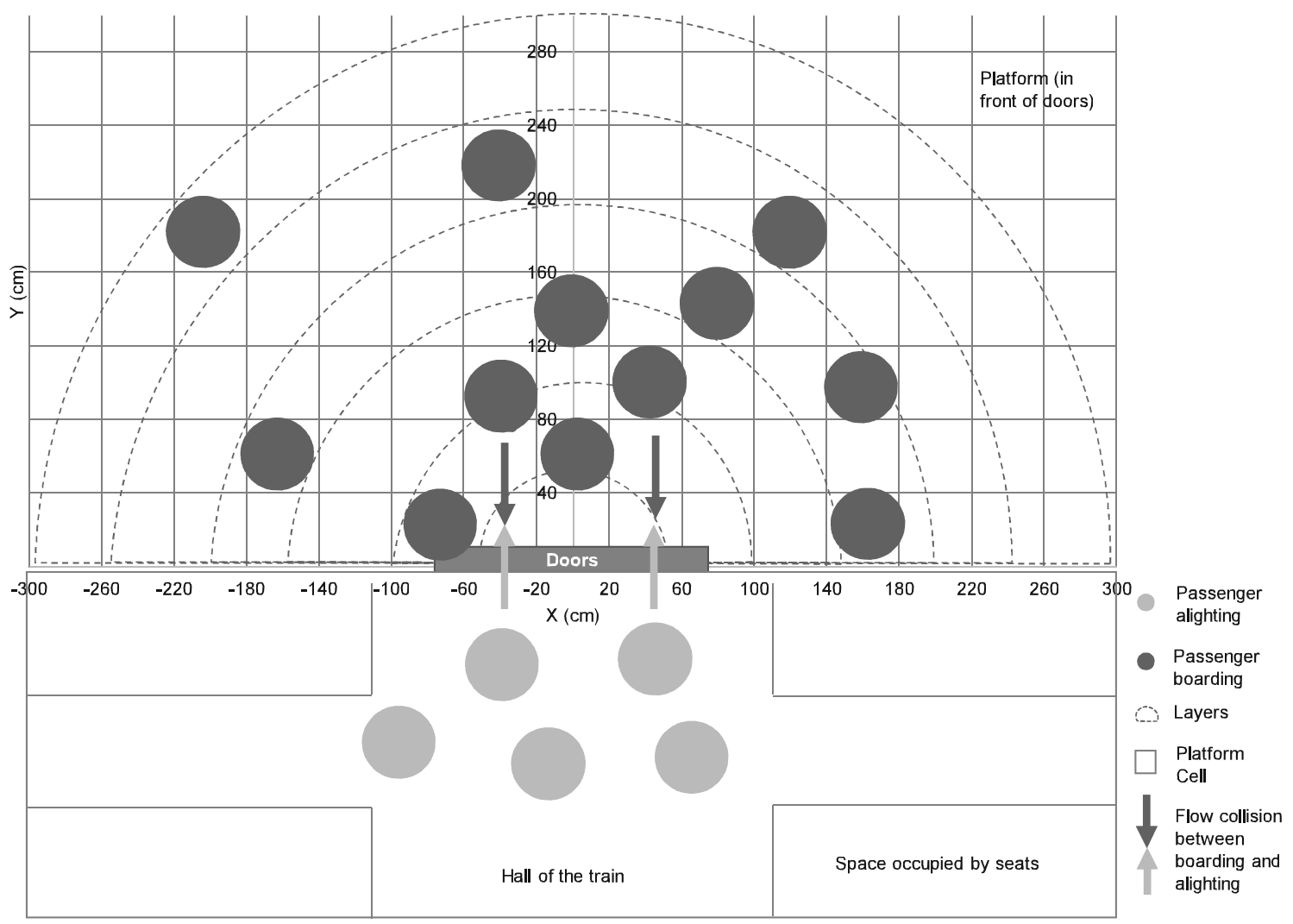

Figure 1: Conceptual model divided in concentric layers of $50 \mathrm{~cm}$ each to measure behaviour and interaction on platforms formed of $40 \mathrm{~cm}$ square cells

Therefore, a high interaction (red colour) will result when there is a situation which creates a risk of accidents with more than 2 pass $/ \mathrm{m}^{2}$ (or more than 4 pass $/ \mathrm{m}^{2}$ for static movement of passengers). A medium interaction (amber colour) is considered when the risk of accidents is reduced (but still is important enough to be taken into account) or when there is a density between 1 pass $/ \mathrm{m}^{2}$ and 2 pass $/ \mathrm{m}^{2}$. The low interaction (green colour) occurs when there is a low risk of accidents with no possible problems or a density lower than 1 pass $/ \mathrm{m}^{2}$. Table 2 shows the degree of interaction as a combination between perception of risk and density between passengers boarding and alighting on the PTI area. Both density and perception of risk are weighted the same for each of the combinations. The highest interaction has a score of 6 , whilst the lowest interaction has a score of 1 . 


\begin{tabular}{|c|c|c|c|c|}
\hline \multirow[b]{2}{*}{ Category } & \multirow[b]{2}{*}{ Variable (comments) [unit] } & \multicolumn{2}{|c|}{ References } & \multirow[b]{2}{*}{ \# } \\
\hline & & $\begin{array}{l}\text { Laboratory } \\
\text { experiments }\end{array}$ & $\begin{array}{l}\text { Field } \\
\text { studies }\end{array}$ & \\
\hline \multirow{4}{*}{ 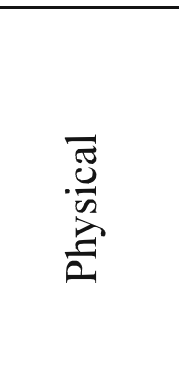 } & Door width [m] & {$[26,27,29]$} & {$[31,34,35]$} & V1 \\
\hline & Vertical and horizontal gap [mm] & $\begin{array}{c}{[25,26,27,} \\
28]\end{array}$ & {$[32,33]$} & V2 \\
\hline & Vertical steps [no. or dimensions] & [30] & {$[32,33]$} & V3 \\
\hline & Platform width [m] & [24] & {$[34,35]$} & V4 \\
\hline \multirow{4}{*}{ 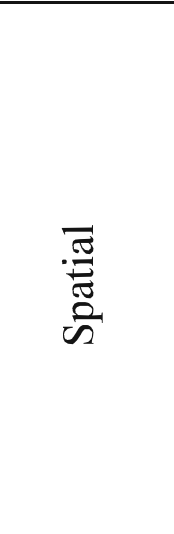 } & $\begin{array}{l}\text { Platform humps (length, width, } \\
\text { and height) [m] }\end{array}$ & [36] & [38] & V5 \\
\hline & Seats and setback [no., m] & [27] & {$[34,35]$} & V6 \\
\hline & $\begin{array}{l}\text { Platform edge doors (half or full } \\
\text { height) [no.] }\end{array}$ & [37] & {$[39,40]$} & V7 \\
\hline & $\begin{array}{l}\text { Poles, barriers and waiting areas, } \\
\text { markings on the floor (position, } \\
\text { width, and length) [no. or m] }\end{array}$ & [2] & {$[39,40,41]$} & V8 \\
\hline \multirow{6}{*}{ 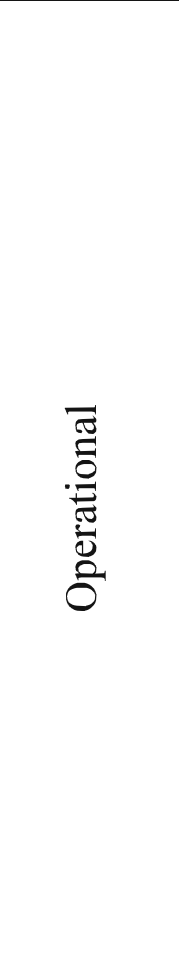 } & $\begin{array}{c}\text { Type of passengers } \\
\text { (demographics, luggage, restricted } \\
\text { mobility, prams) [no.] }\end{array}$ & [30] & \multirow{6}{*}{$\begin{array}{c}{[31,32,33,} \\
34,35]\end{array}$} & V9 \\
\hline & $\begin{array}{c}\text { Density (boarding, alighting, on- } \\
\text { board passengers) [no., or } \\
\left.\text { pass } / \mathrm{m}^{2}\right]\end{array}$ & [13] & & V10 \\
\hline & $\begin{array}{c}\text { Passenger space (distance between } \\
\text { passengers, area occupied) [m or } \\
\left.\mathrm{m}^{2}\right]\end{array}$ & [13] & & V11 \\
\hline & $\begin{array}{l}\text { Location on the platform, } \\
\text { formation of lanes and types of } \\
\text { queues [no.] }\end{array}$ & {$[13,37]$} & & V12 \\
\hline & Flow (at the doors) [pass/min-m] & {$[25,27,29]$} & & V13 \\
\hline & $\begin{array}{l}\text { Boarding and alighting times } \\
\text { (BAT) [s] }\end{array}$ & {$[26,30,37]$} & & V14 \\
\hline
\end{tabular}

Table 1: Variables that affect the behaviour and interaction of passengers boarding and alighting on the PTI area 


\begin{tabular}{|c|c|c|c|}
\hline \multirow{2}{*}{ Perception of risk } & \multicolumn{3}{|c|}{ Density } \\
\hline & Low & Medium & High \\
\hline Low & 1 & 2 & 4 \\
\hline Medium & 2 & 3 & 5 \\
\hline High & 4 & 5 & 6 \\
\hline Key: & & & \\
\hline
\end{tabular}

Table 2: Degree of interaction between passengers boarding and alighting on the PTI area

\subsection{Matrix}

Fourthly, a matrix is created. The results of assigning each variable (from Table 1) one degree of interaction (from Table 2) are presented in a matrix that groups the variables according to the area where the interaction happens (vehicle, PTI, or platform) and to the type of users that are affected by this interaction (boarders only, alighting passengers only, or both). Since there are three types of interactions and three different areas, the matrix has 3 rows and 3 columns.

This way of displaying the results helps to communicate the interaction problems to the relevant decision makers more effectively. For example, if interaction problems arise in the vehicle, then the manufacturing company that designed the vehicle should be contacted. On the contrary, if high interactions happen on the platform, then it is the station managers who should be informed. In the case of a problem at the PTI, then it is the platform guard who needs to be contacted.

Similarly, for the other matrix dimension (types of users), the framework helps to look for the correct action in terms of information. For example, if high interactions are affecting alighting passengers, then announcements could be made inside the vehicle. However, if problems are related to boarding passengers, then the announcements should be made by the station manager or platform guard at the relevant platform or station.

The framework could be used as a diagnosis tool to identify potential problems that could be addressed with the application of crowd management measures. After this initial diagnosis, problems that affect behaviour and interaction can be studied in more detail. Each variable from Table 1 can be measured by observation at stations or laboratory experiments. In the next section, this framework is applied to two London Underground stations.

\section{Case study on the London Underground}

BAMBI was applied to a case study on the London Underground (LU). To this aim, two stations were selected: Westminster (WMS) and Green Park (GPK). Both stations 
are important interchanges on the Jubilee line. The main difference between them is that WMS has platform edge doors (PEDs) and a single grey line $1.2 \mathrm{~m}$ long by 10 $\mathrm{cm}$ wide in front of each door, which act as door position indications on platforms, whilst GPK does not.

Table 3 shows the application of the framework matrix using BAMBI at GPK. To identify the variables from Table 1, site visits were done during peak hours (8:15-9:15 AM and 5:15-6:15 PM). The visits were completed on the 5th (GPK) and 6th (WMS) November 2014, which were the first two days of CCTV recording, as explained below. During these visits, 30 trains per hour were registered, i.e. 120 boarding and alighting events were observed during the two days. Different instruments were used on the site visits, such as digital cameras to take pictures and measuring tapes to obtain the dimensions of the vehicle, PTI, and platform of both stations (GPK and WMS). The main variables that have an impact on the behaviour and interaction of passengers (only boarding, boarding and alighting, and only alighting) were highlighted by means of observation. Possible problems were identified at the vehicle, PTI, and platform.

Another way to represent interaction problems at GPK is shown in Figure 2. According to the type of users, boarding and alighting represent the most critical situation of interaction reaching a total degree of 13 points. With respect to the type of infrastructure, the platform reached the highest degree of interaction problems with 16 points.

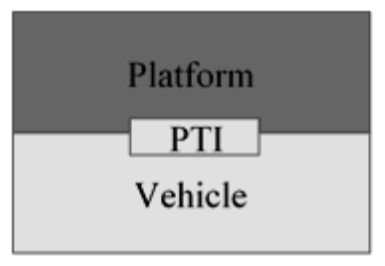

Only boarding

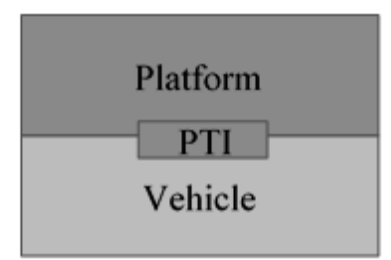

Boarding and alighting

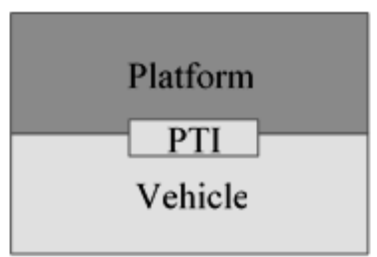

Only alighting

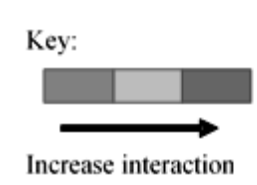

Increase interaction

Figure 2. Interaction maps by category of user and type of infrastructure at GKP

The same framework was applied to WMS. This station presents the same problems of high interactions as GPK. The only difference is that the use of PEDs at WMS reduced the density and perception of risk, as PEDs work as sliding barriers that prevent passengers from falling onto the tracks. In addition, PEDs serve as door position indications on the platform, and therefore the behaviour of passengers changed to waiting beside the doors rather than in front of them.

The analysis using the framework in Table 3 is focused on the critical door (most congested). The critical door was defined previously by LU operators, in which the cameras were installed on the station. In terms of layout, the critical door was located near the entry or exit gate on the platform, where high densities were reached. In both stations, one set of double doors (1.6 m wide in total) was studied. The layout of the 


\begin{tabular}{|c|c|c|c|}
\hline $\begin{array}{l}\text { BAMBI } \\
\text { matrix }\end{array}$ & Only boarding & Boarding and alighting & Only alighting \\
\hline \multirow[t]{2}{*}{ Vehicle } & $\begin{array}{l}\text { Although trains have } \\
20 \text { seats (V6) per } \\
\text { carriage and a } \\
\text { setback } 200-300 \mathrm{~mm} \text {, } \\
\text { in some cases it is } \\
\text { not sufficient to } \\
\text { allocate passengers } \\
\text { boarding (V10) in } \\
\text { the hall or entrance } \\
\text { of the train, reaching } \\
\text { a medium density } \\
\text { and a low perception } \\
\text { of risk. }\end{array}$ & $\begin{array}{l}\text { Passengers on-board } \\
\text { (V10) affect the flow } \\
\text { (V13) and BAT (V14). } \\
\text { In some cases, } \\
\text { passengers cannot } \\
\text { board or alight the } \\
\text { train. Pressure on } \\
\text { passengers being stuck } \\
\text { at the doors. This } \\
\text { situation produces } \\
\text { medium density and } \\
\text { medium perception of } \\
\text { risk. }\end{array}$ & $\begin{array}{l}\text { Although the vertical } \\
\text { pole (V8) in the train } \\
\text { hall is displaced from } \\
\text { the centre, it produces } \\
\text { on-board passengers } \\
\text { (V10) agglomeration, } \\
\text { being in some cases } \\
\text { an obstacle for those } \\
\text { who are alighting, } \\
\text { reaching a medium } \\
\text { density and a low } \\
\text { perception of risk. }\end{array}$ \\
\hline & Degree: 2 & Degree: 3 & Degree: 2 \\
\hline \multirow[t]{2}{*}{ PTI } & $\begin{array}{l}\text { Although vertical } \\
\text { and horizontal gaps } \\
\text { (V2) are small, few } \\
\text { boarders presented } \\
\text { reduced mobility } \\
\text { (V9), reaching low } \\
\text { density and medium } \\
\text { perception of risk for } \\
\text { passengers boarding. }\end{array}$ & $\begin{array}{l}\text { Although double doors } \\
\text { are } 1.6 \mathrm{~m} \text { wide (V1), } \\
\text { the high density (V10) } \\
\text { produced only one } \\
\text { lane of flow (V12) for } \\
\text { alighting and two lanes } \\
\text { of flow for boarding. } \\
\text { Pressure and "confined } \\
\text { flow", reaching a high } \\
\text { density and a medium } \\
\text { perception of risk. }\end{array}$ & $\begin{array}{l}\text { Although vertical and } \\
\text { horizontal gaps (V2) } \\
\text { are small, few } \\
\text { alightering passengers } \\
\text { presented reduced } \\
\text { mobility (V9). This } \\
\text { situation presents low } \\
\text { density and medium } \\
\text { perception of risk for } \\
\text { passengers alighting. }\end{array}$ \\
\hline & Degree: 2 & Degree: 5 & Degree: 2 \\
\hline \multirow[t]{2}{*}{$\begin{array}{l}\text { Plat- } \\
\text { form }\end{array}$} & $\begin{array}{l}\text { Without PEDs (V7) } \\
\text { passengers do not } \\
\text { know where the } \\
\text { doors are, so they are } \\
\text { located (V12) in } \\
\text { front of the doors } \\
\text { rather than beside } \\
\text { them. In addition, } \\
\text { passengers can fall } \\
\text { onto the tracks, } \\
\text { reaching a high } \\
\text { density and high } \\
\text { perception of risk. }\end{array}$ & $\begin{array}{l}\text { The lack of markings } \\
\text { on the floor (V8) does } \\
\text { not identify which part } \\
\text { of the platform should } \\
\text { be used as waiting or } \\
\text { circulation area. } \\
\text { "Crossing flows" and } \\
\text { collisions are produced } \\
\text { with high density and } \\
\text { medium perception of } \\
\text { risk for passengers } \\
\text { boarding and alighting. }\end{array}$ & $\begin{array}{l}\text { The high density } \\
\text { (V10) on the platform } \\
\text { produces that } \\
\text { boarding passengers } \\
\text { are considered an } \\
\text { obstacle for alighting. } \\
\text { Pressure and } \\
\text { "confined flow", } \\
\text { reaching high density } \\
\text { and medium } \\
\text { perception of risk. }\end{array}$ \\
\hline & Degree: 6 & Degree: 5 & Degree: 5 \\
\hline
\end{tabular}

Table 3: Framework matrix applied to GPK (variables from Table 1within parenthesis) 
train corresponded to the rolling stock made in 1996. These trains have a setback (distance between the doors and the seats inside the train) between $200 \mathrm{~mm}$ and 300 $\mathrm{mm}$, one vertical pole in the hall or entrance, and 20 seats per carriage, approximately. In the case without PEDs (GPK), the vertical gap reached $170 \mathrm{~mm}$, whilst at WMS (with PEDs), there is no vertical gap between the train and the platform. In both cases, the horizontal gap is $90 \mathrm{~mm}$ and the platform width is $3.0 \mathrm{~m}$.

From the analysis in Table 3, it can be concluded that four variables are related to problems of high interactions (as a combination of density and perception of risk) at both stations:

- PEDs (V7);

- markings on the floor (V8);

- density (V10);

- location on the platform and formation of lanes (V12).

To understand these problems and identify possible solutions to reduce the interaction between passengers boarding and alighting, a more detailed study is needed at both stations.

To study the interaction and behaviour on the platform and PTI areas, observations on both stations were carried out using CCTV footage from one week of recording (weekdays from 5th November to 11th November 2014). Because of the location of the cameras, it was not possible to observe the behaviour of passengers inside the train. Therefore, this paper will focus on the platform and PTI area, however this does not mean that other spaces do not need a detailed analysis. Further research should be carried out to include these other analyses.

Data was analysed using the software Observer XT11 and the videos were converted into avi format with the software Nucleus. To process the images with Observer XT11, two types of codes were used [49]: to establish the time (e.g. "boarding 0-5 s" which means segment 0 to 5 seconds), and to register an event (e.g. "B0-5s 1" which means that one passenger boarded in the segment between 0 and 5 s). In total, six types of events were processed: train arrival, passenger entering PTI, door opening, boarding or alighting, last passenger exiting PTI, door closing. The period of analysis was between the door opening and closing times. The behaviour and interaction of passengers was obtained for peak hours (8:15-9:15 AM and 5:156:15 PM). During this period, an average frequency of 30 trains per hour operates, so that in total about 600 boarding and alighting events were analysed.

To measure the density (V10), the number of passengers waiting to board (B) the train was counted using the conceptual model proposed in Figure 1. Each time a train stopped at the station, a cell was assigned to B using the conceptual model. The number of passengers alighting (A) was counted every 5 seconds. It was not possible to obtain the number of passengers on-board arising from the location of the cameras hanging from the platform ceiling.

Similarly, the location of passengers on the platform and formation of lanes for alighting (V12) was measured using the conceptual model proposed in 
Figure 1 1. In the case of WMS (with door position indications on the platform), the number of passengers waiting to board the train (B) was measured just before the train doors opened. However, at GPK (without markings) B was measured between 2 and 3 seconds before the train stopped at the platform to correct for possible last moment passenger movements to adjust their position once they could guess the final location of the train doors. The centre of the doors is considered as the starting point $(0,0)$ for the variable V12.

In the case of the number of passengers alighting (A), a lane of flow was defined as one or more passengers walking one behind another. With the $1.6 \mathrm{~m}$ wide double doors at WMS and GPK, between one and two lanes could be formed for alighting. Therefore, the formation of lanes was coded into four categories: zero (no alighting passengers), one lane, two lanes, and between one and two lanes.

The formation of lanes for alighting was compared to the ratio $\mathrm{R}=\mathrm{B} / \mathrm{A}$. In this paper it is expected to identify the relationship between the formation of lanes and the value of R. In the following sections the results of the observation at WMS and GPK are presented.

\subsection{Formation of lanes}

Figure 3 shows the frequency of events at both stations with respect to five categories of the ratio $\mathrm{R}$ (passengers waiting to board/passengers alighting) at both stations. From the total of events studied (600 approximately), $26 \%$ of them presented a value of $\mathrm{R}$ around 1.0, which means that there was a similar number of passengers boarding and alighting at the critical door. Few cases presented a $\mathrm{R}=0.25$ (or less), which means that in most cases there were more passengers boarding than alighting. This is also noticed in the case of $\mathrm{R}=4$ (or more), which occurred in $20 \%$ of the observations.

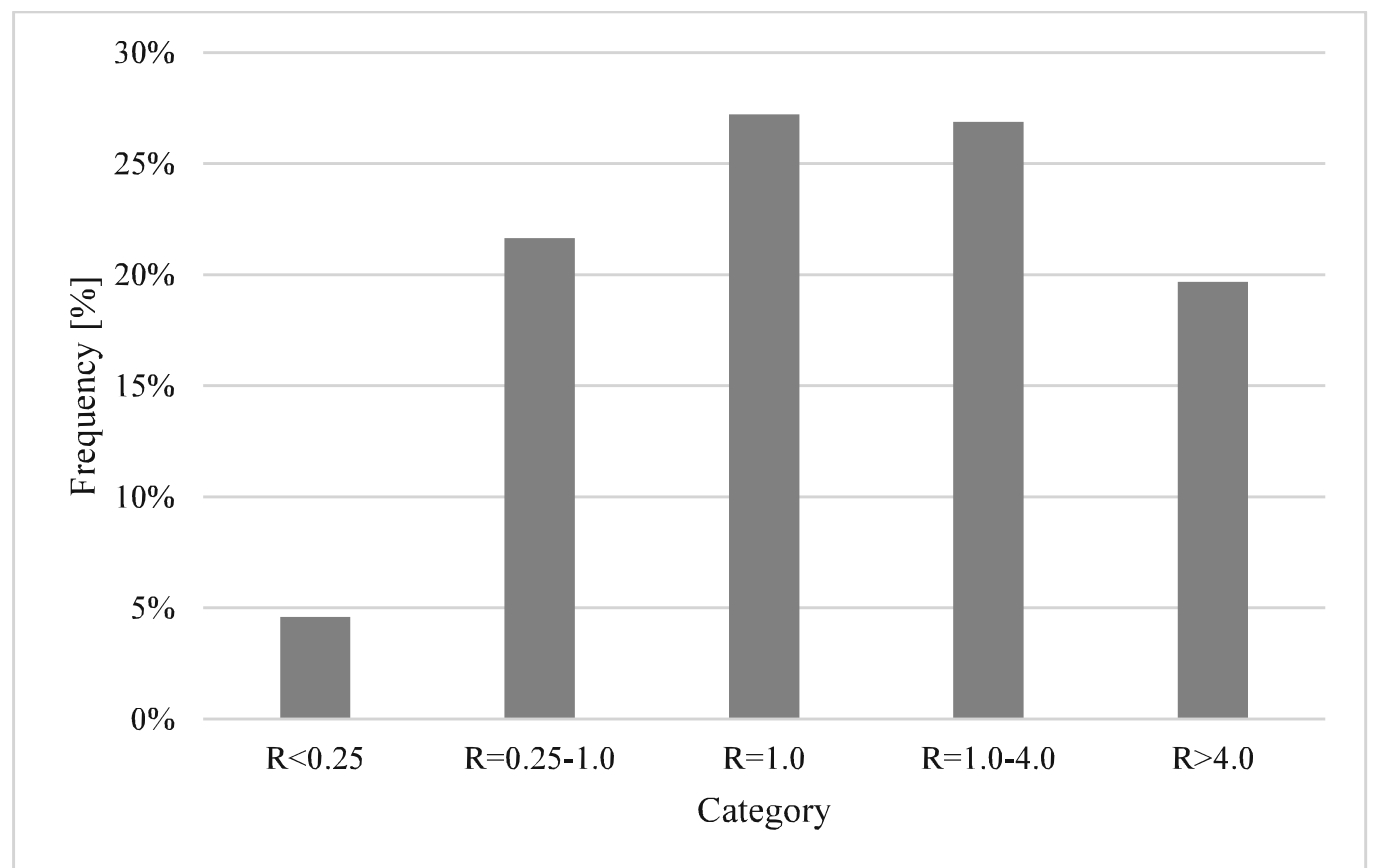

Figure 3. Frequency of events by category of R (B/A) at GKP and WMS 
Figure 4 shows the relationship between the number of lanes formed for alighting and the ratio $\mathrm{R}(\mathrm{B} / \mathrm{A})$ at both stations. For low $\mathrm{R}(\mathrm{R}<0.25)$ up to two lanes for alighting are formed, reaching $60 \%$ of the cases in that category, whilst the other $40 \%$ of the cases presented between one and two lanes for alighting. The two lanes are formed as a result of the available space on the platform. When this space is reduced, then the number of lanes is reduced, too. When there are between one and two lanes, it means that during the process of alighting passengers formed one and sometimes two streams of flow to get off the train. In this category $(\mathrm{R}<0.25)$, practically no cases presented only one lane for alighting.

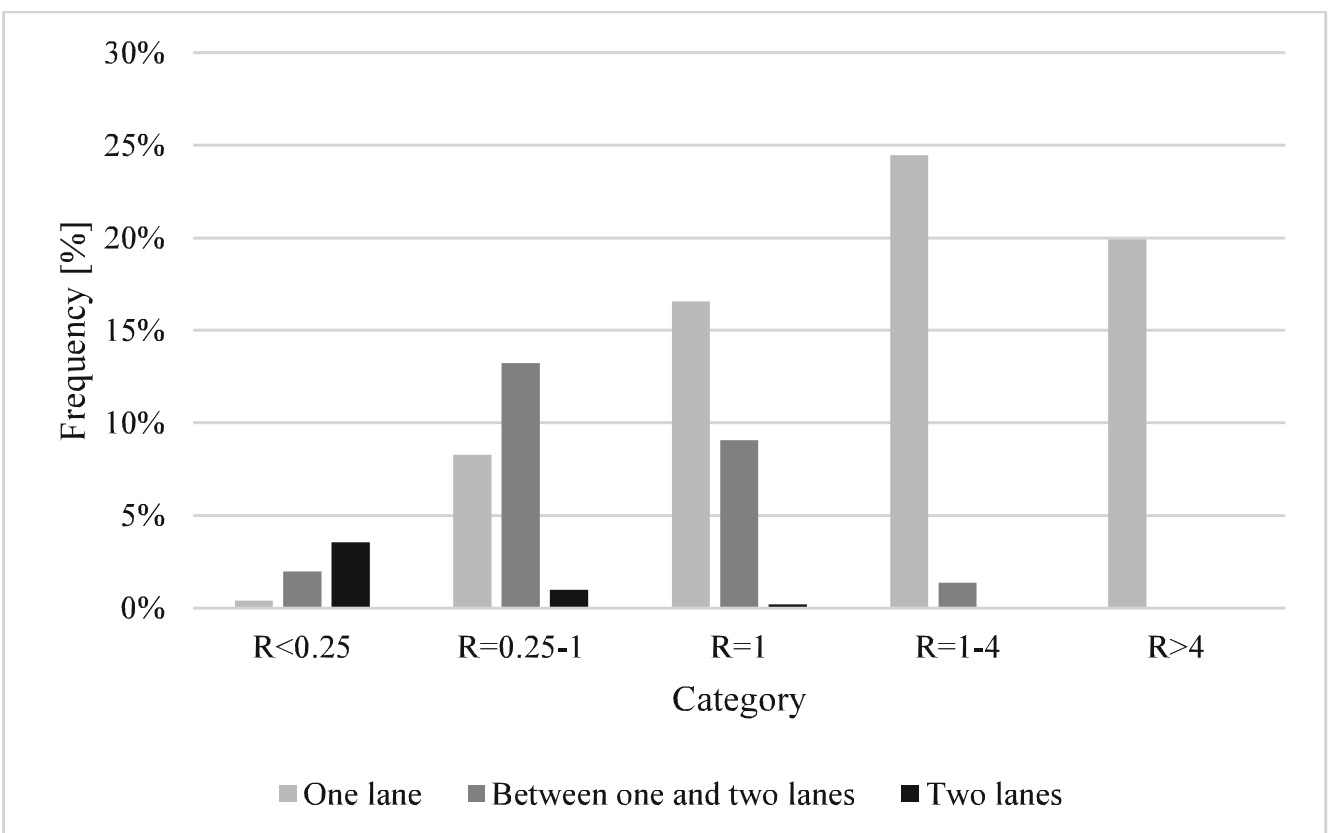

Figure 4. Relationship between number of lanes and R (B/A) at GKP and WMS

As the value of $\mathrm{R}$ increases, the number of lanes is reduced. In Figure 4, within the category $\mathrm{R}=1,64 \%$ of the cases show only one lane for alighting, whilst the rest of the observations in that category present between one and two lanes. In this category $(\mathrm{R}=1)$, virtually no events showed two lanes for alighting.

For high values of R ( 4 or more), Figure 4 shows that only one lane for alighting was formed in all cases. In this category, the high pressure of passengers trying to board reduces the space for passengers to get off the train, therefore only a single narrow lane is formed for alighting.

\subsection{Location of passengers waiting to board the train}

Figure 5 shows the average location (in terms of layers) of passengers on the platform waiting to board the train (B) at GPK for the AM and PM peak hours. On average, B $=11$ passengers are distributed in six layers. The first layer $(0-50 \mathrm{~cm})$ is not used, as a result of the yellow safety line, which is respected by passengers. The last layer $(>300 \mathrm{~cm})$ is not used either because this space is occupied by passengers walking 
along the platform to and from the entrances. The third, fourth and fifth layers are the most congested spaces, reaching 2 passengers on average. This means that the most used space is between $1 / 3$ and $2 / 3$ of the platform width. The same distribution of passengers is obtained at WMS, with a similar profile.

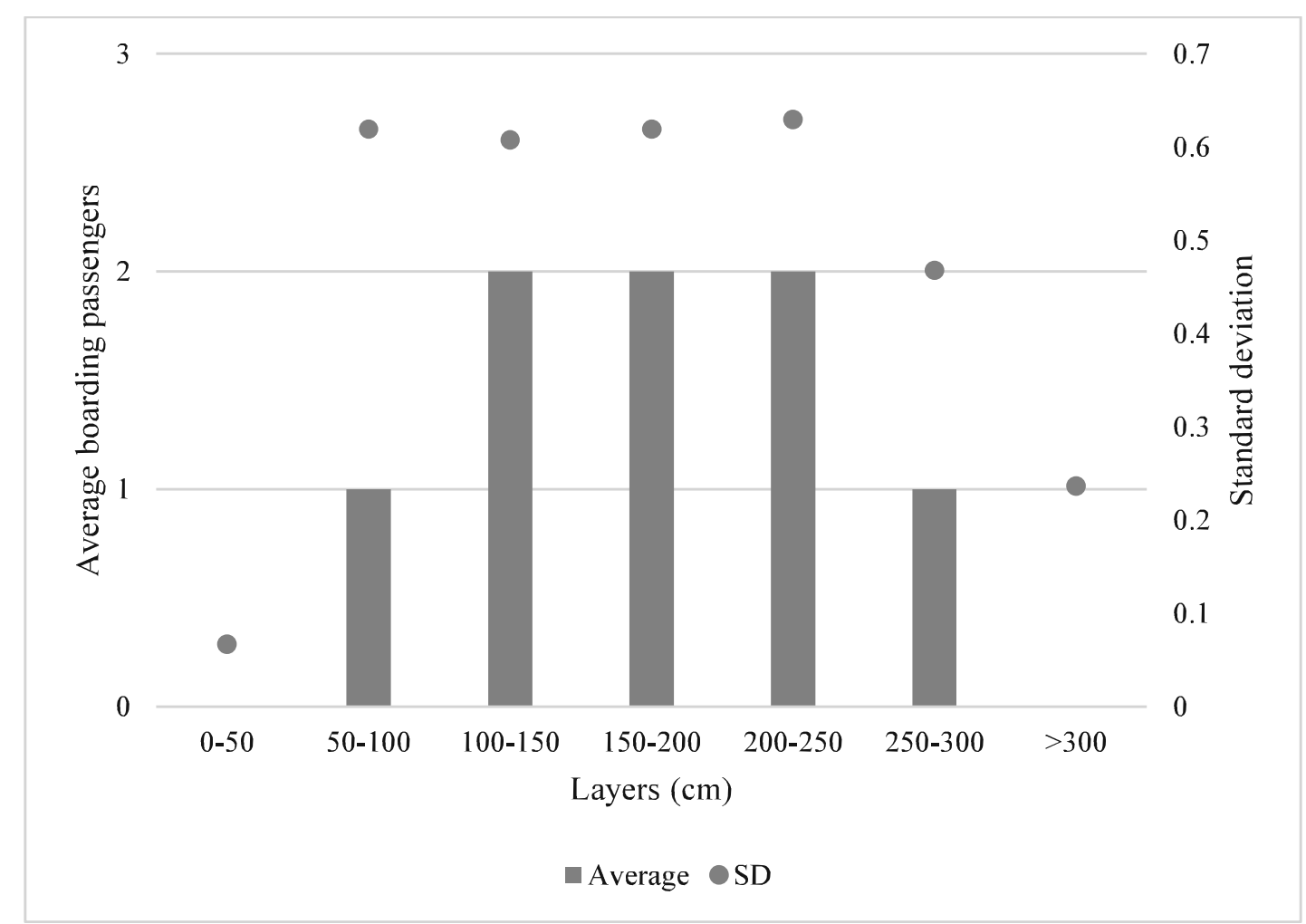

Figure 5: Average location of passengers on the platform waiting to board the train at GPK in the AM and PM peak hours

As a complementary visualisation tool of the distribution of passengers on the platform by layers, Figure 6 shows the interaction maps at both stations. These maps represent the average number of times each $40-\mathrm{cm}$ cell is used by one passenger waiting to board the train. Therefore, the maps represent the density of passengers and potential risks based on the framework, such as agglomeration, high pressure, "crossing of flows", collision and "confined flow" (see Table 3). The green colour represents a low interaction area, whilst the red colour denotes high interactions. Medium interactions are symbolised in an amber colour.

In Figure 6, the differences between both stations are clear. In the case of WMS, the use of PEDs acting as door position indications on the platform change the behaviour of passengers to waiting beside the doors rather than in front of them. Cells G5 and G9 are the most used cells at WMS. However, the cells in front of the doors (e.g. F6, F7) are less used at WMS compared to GPK, where no door position indications on platforms are used. Thus, these door indicators help passengers alighting to get off the train with fewer interaction problems.

In the case of GPK, Figure 6 shows that passengers are more evenly distributed on the platform, but less clustered as they do not know where the train is going to stop. 
Cells in front of the door at GPK (e.g. F6, F7) are used up to 2.7 times more compared to the same cells at WMS, causing high interaction problems. Passengers waiting to board the train at GPK do respect the yellow safety line on the platform, therefore the first row of cells (row $\mathrm{G}$ ) is less used on average. This produces a reduction of $40 \mathrm{~cm}$ or $13 \%$ less platform compared to WMS, in which all the platform width is used.

The standard deviation of the number of times each cell is used was also calculated for the 5 day sample (AM and PM). In both cases (GPK and WMS), the standard deviation resulted in a range between 0 to 4 . The standard deviation decreases as the distance from the doors increases, i.e. $\mathrm{t}$

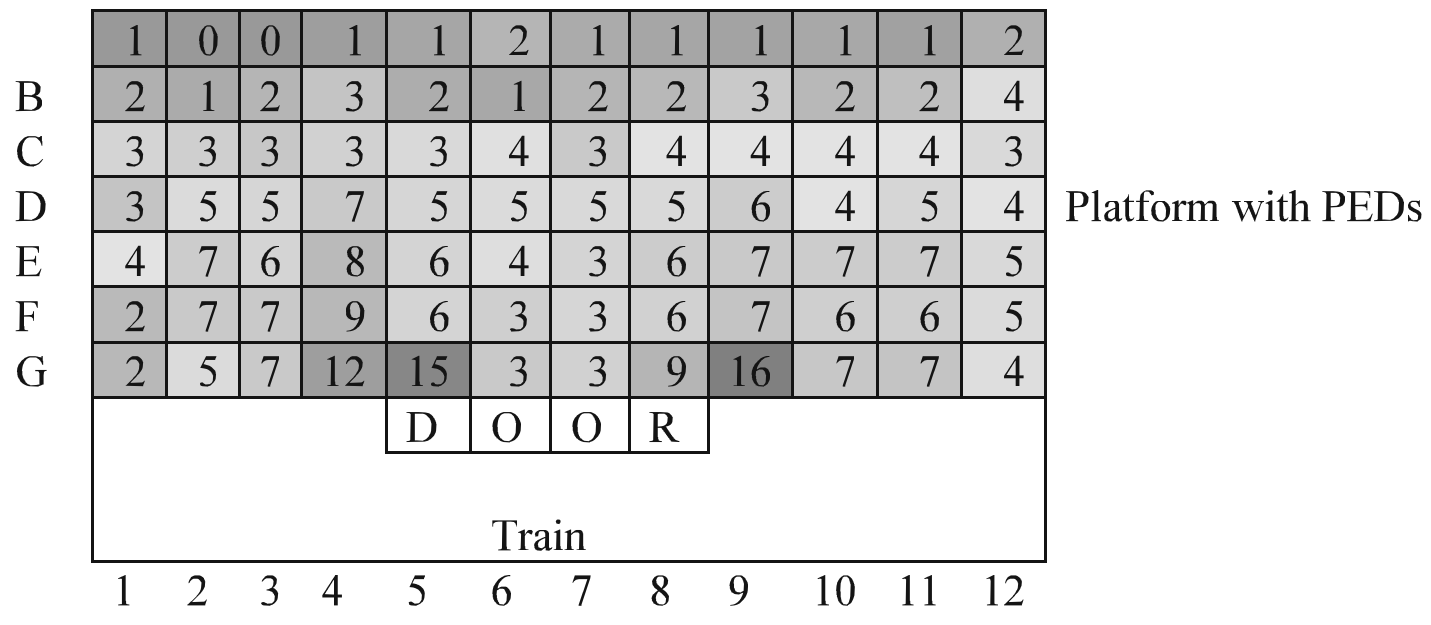

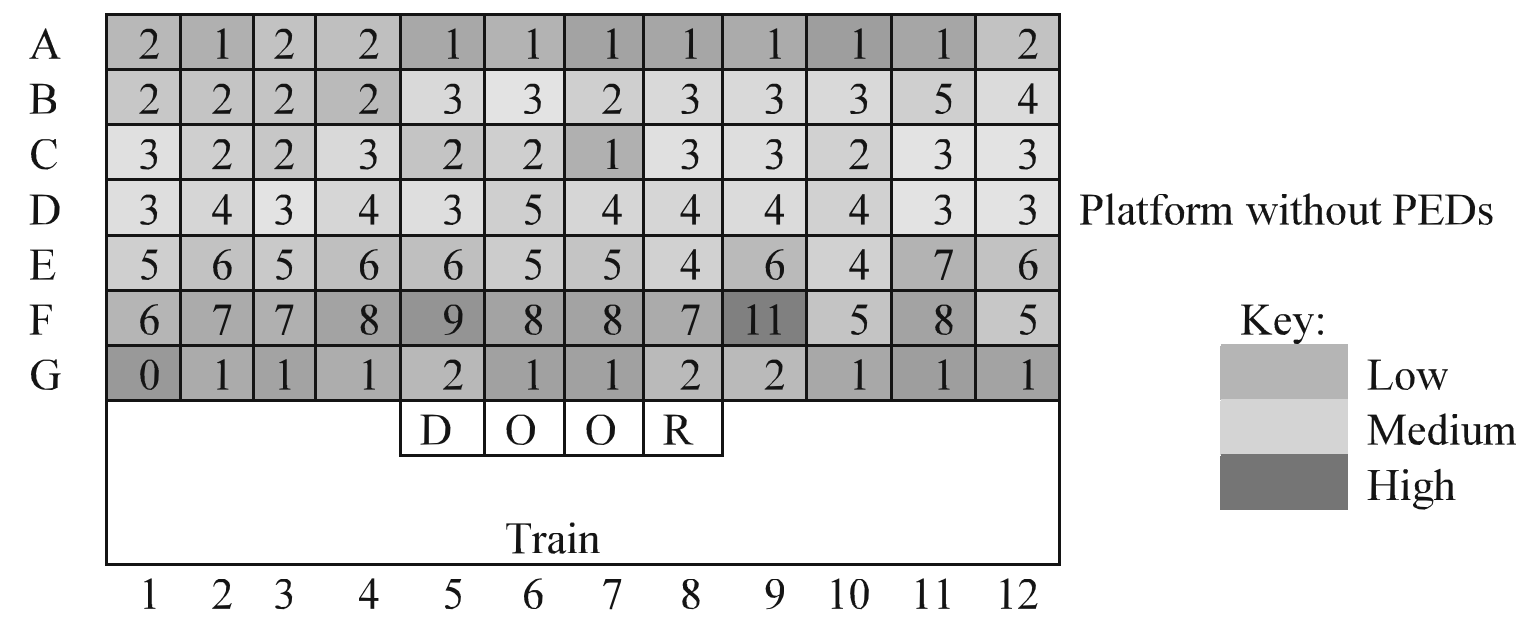

Figure 6: Average interaction maps on the platform at WMS (with PEDs) and GPK (without PEDs)

\section{Discussion}

In this paper, a new framework has been proposed to analyse the behaviour and interaction of passengers at platform train interfaces (PTI) when crowd management measures are used. This framework could help to identify potential problems at an 
ea

e.g. choosing the best crowd management measure). This matrix is different from existing studies $[9,20]$ as it is applied to metro stations in normal operations with high densities to evaluate crowd management measures such as platform edge doors (PEDs). In addition, this framework gives more information compared to existing indicators, such as the Level of Service or LOS in [10]. The LOS is based only on average values of overall density; however, this framework uses the density by layer and the perception of risk to identify the interaction between passengers boarding and alighting at the PTI.

The new framework is named BAMBI (Boarding and Alighting Matrix on Behaviour and Interaction), and consists of four stages. The first stage is the conceptual model to represent the movement of passengers boarding and alighting. In the second stage, variables are identified. In the third stage, the degree of interaction (density and perception of risks) between passengers is defined as high, medium and low. Finally, a matrix is proposed to present the results according to the area (vehicle, PTI, and platform) and the type of user (boarders only, alighting passengers only, or both) in a specific station. Existing frameworks [24, 25, 26] do not include these stages as they are focused on evacuation scenarios at metro stations and do not consider the use of PEDs at the PTI or any other crowd management measure.

BAMBI was applied to two stations (with and without PEDs) in the London Underground. The new framework successfully described the phenomena of high interactions between passengers boarding and alighting. The conceptual model was used to identify interaction maps at both stations. The use of maps helps to identify which part of the PTI area is more congested or potentially presents higher risks, which was more representative of the interaction problems than using average values as reported in [10]. Variables, such as door position indications on platforms (e.g. the use of PEDs, markings on the floor), density, formation of lanes and location of passengers on the platform appeared to be the most important variables that produced high interaction problems at both stations.

A complete observation of peak hours during one week was performed to understand those problems by means of CCTV footage. From the observations at both stations, it can be concluded that passengers are mostly located between $1 / 3$ and $2 / 3$ of the total width of the platform. In addition, the use of PEDs can reduce the interaction between passengers. In particular, PEDs changed the behaviour of passengers to waiting beside the doors rather than in front of them. For example, when there were no door indicators (without PEDs), the space in front of the doors was used up to 2.7 more times than in the case with PEDs, which causes high interaction between passengers.

With respect to the formation of lanes, as the ratio $\mathrm{R}$ between passengers waiting to board the train and those who are alighting increases, the number of lanes for alighting decreases. When $\mathrm{R}=0.25$ (or less), $60 \%$ of the observations presented two lanes for alighting. These two lanes were formed as a result of the available space on 
the platform. On the other hand, when $\mathrm{R}=4$ (or more) passengers on the platform produce a high interaction to board and therefore only one narrow lane for alighting can be formed. In the case $\mathrm{R}=1,35 \%$ of the observations had between one and two lanes for alighting.

To reduce the problems of interaction between passengers boarding and alighting at Green Park (GPK), PEDs and markings on the platform can be included as door indicators. In practice, different metro systems in Singapore, Washington and Tokyo have already tested some crowd management measures on platforms [ $46,47,50]$. In the case of the London Underground, the position of the yellow safety line on the platform has been moved back in some stations as a trial, producing some cross hatch door bays or "keep out zones" [51]. However, limited analysis has been carried out to identify which measures are more effective. Further research is needed to identify which type of crowd management measure should be used considering each condition and effect on platforms.

In the case of GPK (without PEDs), the train stops at the same position on the platform each time it arrives at the station. This is because the train occupies the whole length of the platform. Figure 7 shows a possible application of crowd management measures at GPK. A "keep out zone" could be used to avoid passengers being an obstacle for those who are alighting. Similar to Seriani and Fernandez [2], the rectangle of this zone should cover the door width, include diagonal lines and the name on the platform. However, in the case of GPK, the depth of the rectangle should be $1.2 \mathrm{~m}$. This depth is obtained according to the interaction maps from Figure 6, which represents the first three rows of cells after the yellow safety line that reached medium or high interactions. Passengers waiting to board the train should be located around this "keep out zone". Compared to some existing field studies, this zone is almost double in size to the one used by LUL [51] at King's Cross St. Pancras, in which the "keep out zone" had a depth of $0.7 \mathrm{~m}$ only.
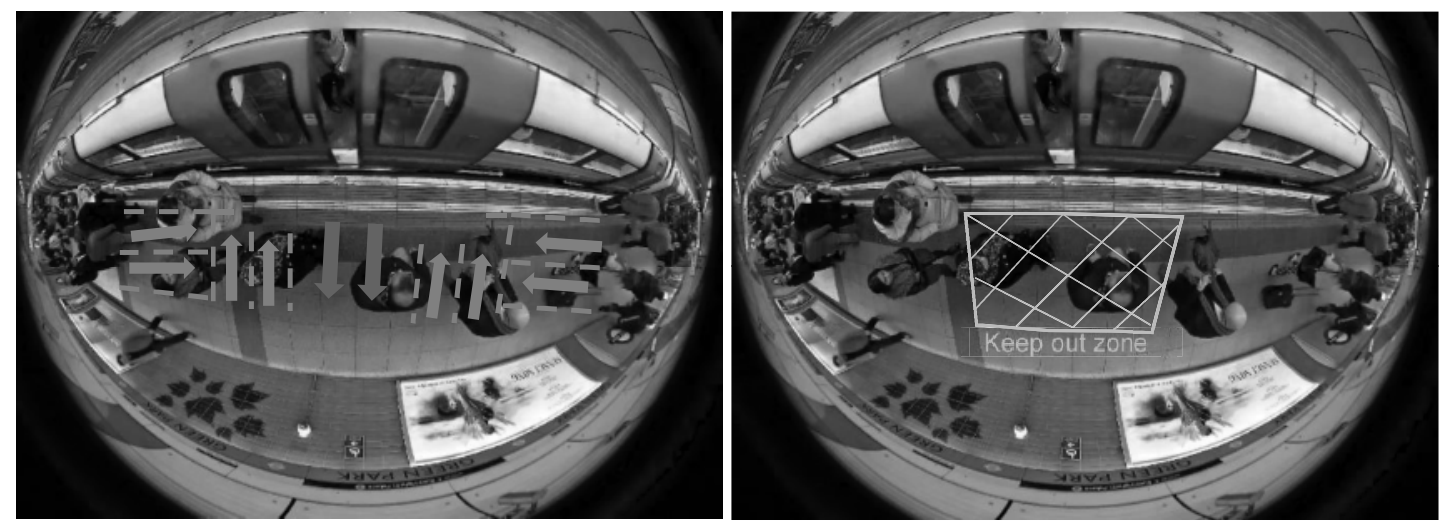

Figure 7. "Keep out zone" (right) and queue lanes (left) to reduce interaction at GPK

Another crowd management measure proposed in Figure 7 is the use of queue lanes. For example, Seriani et $a l$. [13] proposed queue lanes of $2.6 \mathrm{~m}$ length by $0.6 \mathrm{~m}$ width for boarding and alighting based on laboratory experiments. In the case of GPK, queue lanes for alighting could be $1.2 \mathrm{~m}$ long by $0.4 \mathrm{~m}$ wide. Similar to the "keep out zone", 
i.e. $1.2 \mathrm{~m}$ long by $0.4 \mathrm{~m}$ wide).

\section{Conclusions}

This research has shown the development and application of a new framework to two existing London Underground (LU) stations. The framework helped to identify the problems of interaction in the boarding and alighting process.

The results show that the framework represented the problems of interaction at the PTI. In the case of formation of lanes, if the value of R (boarding / alighting) increases, then the number of lanes for alighting decreases. With respect to the location of passengers on the platform, boarding passengers are distributed at the side of the doors rather than in front of the doors when PEDs are used.

To reduce the interaction between passengers, crowd management measures are proposed. Solutions such as a "keep out zone" would help to avoid passengers standing in front of the doors and reduce interaction for those who are alighting. Another solution presented in this paper was the implementation of queue lanes for boarding and alighting. Up to two queue lanes are needed for alighting, while queues for boarding could be divided into perpendicular and parallel to the doors, needing a minimum of four each side of the door.

This paper studied the behaviour and interaction of passengers on the LU, however the framework and results could be expanded to any conventional rail or LRT system. Other limitations of the study were related to the location of cameras, in which onboard passengers could not be captured. Further research is needed to include these passengers and capture interactions inside the train. In addition, new laboratory experiments and field studies are needed to identify which type of crowd management measures are more effective, considering each condition and their effect on platforms.

\section{Acknowledgements}

The authors would like to thank Transport for London for providing the videos, software and data needed for this research. 


\section{References}

[1] RSSB, "Platform Train Interface Strategy", London: Rail Safety and Standards Board, 2015, [accessed 2016 Aug 19], available from: http://www.rssb.co.uk/improving-industry-performance/platform-t interface.

[2] S. Seriani, R. Fernandez, "Pedestrian traffic management of boarding and alighting in metro stations", Transportation research part C: Emerging Technologies, 53, 76-92, 2015.

[3] C.K. Law, P.S. Yip, "An economic evaluation of setting up physical barriers in railway stations for preventing railway injury: evidence from Hong Kong", Journal of epidemiology and community health, 65(10), 915-920, 2011.

[4] M. Kyriakidis, R. Hirsch, A. Majumdar, "Metro railway safety: An analysis of accident precursors", Safety Science, 50(7), 1535-1548, 2012.

[5] E. Kroes, M. Kouwenhoven, L. Debrincat, N. Pauget, "Value of Crowding on Public Transport in Île-de-France, France", Transportation Research Record, 2417, 37-45, 2014.

[6] LUL, "New tube for London. Feasibility Report. London: London Underground Limited", 2014, [accessed 2016 Apr 26], available from: http://content.tfl.gov.uk/ntfl-feasibility-report.pdf.

[7] C. Stenström, A. Parida, D. Galar, "Performance Indicators of Railway Infrastructure", International Journal of Railway Technology, 1(3), 1-18, 2012.

[8] K. Still, "Crowd Dynamics", [dissertation], Coventry (UK): University of Warwick, 2000.

[9] K. Still, "Introduction to Crowd Science", Boca Raton (FL): CRC Press, 2013.

[10] J.J Fruin, "Designing for pedestrians: a level-of-service concept", Highway Research Record, 377, 1-15, 1971.

[11] S.P. Hoogendoorn, W. Daamen, "Pedestrian behaviour at bottlenecks", Transportation Science, 39(2), 147-159, 2005.

[12] A. Seyfried, T. Rupprecht, O. Passon, B. Steffen, W. Klingsch, M. Boltes, "New insights into pedestrian flow through bottlenecks", Transportation Science, 43, 395-406, 2009.

[13] S. Seriani, T. Fujiyama, C. Holloway, "Exploring the pedestrian level of interaction on platform conflict areas at metro stations by real-scale laboratory experiments", Transportation Planning and Technology, 40(1), 100-118, 2017.

[14] G.W. Evans, R.E. Wener, "Crowding and personal space invasion on the train: Please don't make me sit in the middle", Journal of Environmental Psychology, 27(1), 90-94, 2007.

[15] H. Yin, D. Li, X. Zheng, "An energy based method to measure the crowd safety", Transportation Research Procedia, 2, 691-696, 2014.

[16] N.D.M Mahudin, T. Cox, A. Griffiths, "Measuring rail passenger crowding: Scale development and psychometric properties", Transportation Research Part F: traffic psychology and behaviour, 15(1), 38-51, 2012.

[17] T. Cox, J. Houdmont, A. Griffiths, "Rail passenger crowding, stress, health and safety in Britain", Transportation Research Part A: Policy and Practice, 40(3), 244-258, 2006. 
[18] RSSB, "Health and safety effects of rail crowding: hazard identification (T307)", London: Rail Safety and Standards Board, 2005, [accessed 2016 Aug 19], available from: http://www.rssb.co.uk/library/research-development-a innovation/research-brief-T307.pdf.

[19] K.M. Kim, S.P. Hong, S.J. Ko, D. Kim, "Does crowding affect the path choice of metro passengers?" Transportation Research Part A: Policy and Practice, 77, 292-304, 2015.

[20] K. Still K, "Visualising risk assessment for crowd safety", Journal of the International Centre for Sports Security, 2(1), 2014, [accessed August 19, 2016], available from: http://icss-journal.newsdeskmedia.com/visualising-riskassessment-for-crowd-safety.

[21] L. F. Miranda-Moreno, P. Morency, A.M. El-Geneidy, "The link between built environment, pedestrian activity and pedestrian-vehicle collision occurrence at signalized intersections". Accident Analysis and Prevention, 43(5), 1624-1634, 2011.

[22] CDM, "Code for Design of Metro. GB 50157-2003", China National Standard, 2003.

[23] NFPA 130, "Standard for Fixed Guideway Transit and Passenger Rail Systems", United States, 2003.

[24] C. Shi, M. Zhong, X. Nong, L. He, J. Shi, G. Feng, "Modeling and safety strategy of passenger evacuation in a metro station in China", Safety Science, 50(5), 1319-1332, 2012.

[25] L. D'Acierno, M. Gallo, B. Montella, A. Placido, "The definition of a model framework for managing rail systems in the case of breakdowns", in "Proceedings of the Intelligent Transportation Systems (ITSC), 16th International IEEE Conference", 1059-1064, 2013.

[26] Q. Li, L. Song, G.F. List, Y. Deng, Z. Zhou, P. Liu, “A new approach to understand metro operation safety by exploring metro operation hazard network (MOHN)", Safety Science, 93, 50-61, 2017.

[27] Q. Zhang, B. Han, D. Li, "Modeling and simulation of passenger alighting and boarding movement in Beijing metro stations", Transportation Research Part C: Emerging Technologies, 16, 635-649, 2008.

[28] M. Davidich, F. Geiss, H.G. Mayer, A. Pfaffinger, C. Royer, "Waiting zones for realistic modelling of pedestrian dynamics: A case study using two major german railway stations as examples", Transportation Research Part C: Emerging Technologies, 37, 210-222, 2013.

[29] P. Clifford, E. Melville, S. Nightingale, "Dynamic Simulation Assessment of Train and Tram Platform Interfaces", paper presented at "European Transport Conference", Sep 29-Oct 1, Frankfurt, 2014.

[30] S. Seriani, R. Fernandez, "Planning guidelines for metro-bus interchanges by means of a pedestrian microsimulation model in Chile", Transportation Planning and Technology, 38(5), 569-583, 2015.

[31] W. Daamen, Y. Lee, P. Wiggenraad, "Boarding and alighting experiments: an overview of the set up and performance and some preliminary results on the gap effects", Transportation Research Record, 2042, 71-81, 2008. 
[32] R. Fernandez, P. Zegers, G. Weber, N. Tyler, "Effect of door width, platform height and fare collection on bus dwell time. Laboratory evidence for Santiago de Chile", Transportation Research Record, 2143, 59-66, 2010.

[33] T. Fujiyama, R. Thoreau, N. Tyler, "The effects of the design factors of the trainplatform interface on pedestrian flow rates", in "Pedestrian and Evacuation Dynamics", U. Weidmann, U. Kirsch, M. Schreckenberg (Editors), Springer International Publishing, 1163-1173, 2012.

[34] X. Karekla, N. Tyler, "Reduced dwell times resulting from train-platform improvements: the costs and benefits of improving passenger accessibility to metro trains", Transportation Planning and Technology, 35(5), 525-543, 2012.

[35] R. Fernandez, A. Valencia, S. Seriani, "On passenger saturation flow in public transport doors", Transportation Research Part A: Policy and Practice, 78, 102$112,2015$.

[36] C. Holloway, R. Thoreau, T-R. Roan, D. Boampong, T. Clarke, D. Watts, "Effect of vertical step height on boarding and alighting time of train passengers", in "Proceedings of the Institution of Mechanical Engineers Part F Journal of Rail and Rapid Transit", 230(4), 1234-1241, 2016.

[37] P.B.L. Wiggenraad, "Alighting and boarding times of passengers at Dutch railway stations - a

$-t$

_vLgMTryumCQTBqYnpTUn

oyaTQ/edit.

[40] N.G. Harris, "Train boarding and alighting rates at high passenger loads", Journal of Advanced Transportation, 40(3), 249-263, 2006.

[41] N.G. Harris, R.J. Anderson, "An international comparison of urban rail boarding and alighting rates", in "Proceedings of the Institution of Mechanical Engineers, Part F: Journal of Rail and Rapid Transit", 221(4), 521-526, 2007.

[42] N. Tyler, C. Childs, D. Boampong, T. Fujiyama, "Investigating ramp gradients for humps on railway platforms", Municipal Engineer, 168(2), 150-160, 2015.

[43] G. De Ana Rodriguez, S. Seriani, C. Holloway, "Impact of platform edge doors on passengers' boarding and alighting time and platform behaviour", Transportation Research Board, 2540, 102-110, 2016.

[44] X. Karekla, T. Fujiyama, N. Tyler, "Evaluating accessibility enhancements to public transport including indirect as well as direct benefits", Research in Transportation Business \& Management, 2, 92-100, 2011.

[45] J. Wu, S. Ma, "Division method for waiting areas on island platforms at metro stations", Journal of Transportation Engineering, 139(4), 339-349, 2013.

[46] A. Loukaitou-Sideris, B.D. Taylor, C.T. Voulgaris, "Passenger Flows in Underground Railway Stations and Platforms MTI Report 12-43", San Jose (CA): Mineta Transportation Institute Publications, 2015. 
[47] WMAT, "Passenger Flow and Train Dwell Time", Washington D.C.: Washington Metropolitan Area Transit Authority, 2015, [accessed 2016 Apr 26], available from: https://www.wmata.com/about_metro/board_of_directors/ board_docs/092205_4cPassengerFlowandDwellTimeFinal.pdf.

[48] LUL, "Station Planning Standards and Guidelines. London: London Underground Limited", 2012, [accessed 2016 Apr 26], available from: http://www.persona.uk.com/nle/B-Core_docs/G/NLE-G1.pdf

[49] The Observer XT software, 2014, [accessed 2 September 2017], available from: http://www.noldus.com/observer

[50] Lim, "On your marks, get set, queue", [internet], The Straits Times, 2015 Oct 5 [cited 2016 Nov 18], [about 2 screens], available from: http://www.straitstimes.com/singapore/transport/on-your-marks-get-set-queue.

[51] LUL, "Yellow line trial", The GAPS Project team, London: London Underground Limited, 2015. 